\title{
Entrevista com Brenda Bazante
}

\author{
ANDREA SOBREIRA DE OLIVEIRA \\ UFPE
}

1 - (Andrea Sobreira Oliveira) Como artista trans pernambucana poderia nos falar como tem sido se inserir nos circuitos das artes visuais, pensando que no Brasil existem lugares de privilégio para se fazer parte deste fluxo?

(Brenda Gomes Bazante) - Desde 2013 eu atuo no campo das Artes Visuais. Entre este ano e o de 2014, fiz performances no SPA das Artes 2013, no Dia do Frevo de Olinda/PE e na Expo Distrito da Luz Vermelha/ Grupo Vaastu na Galeria Mau Mau, em Recife/PE. Também posei como modelo vivo para diversos grupos/aulas de desenho, entre eles o Risco e o C.A.S.A, ambos de Recife. Em 2015 iniciei a Graduação em Artes Visuais e, além das seções de modelo que fazia no IFPE/Campus Olinda, comecei a trabalhar com esculturas cinéticas. A partir daí, realizei, entre 2016 e 2018, seis ações com a Expo Galhos. Foram cinco exposições individuais e uma coletiva que passaram pelo Engenho Massangana/ Cabo de Santo Agostinho (PE), Muhne/Recife, Torre Malakoff/Recife, Solar da Marquesa/Olinda e outros lugares. Em todas estas ações eu fui artista convidada, organizadora, voluntária ou fui artista selecionada, como foi o caso do $2^{\text {a }}$ Festival Sonora, realizado em Olinda no ano de 2018.

Não sei dizer se essas ações fazem parte do Circuito das Artes em Pernambuco. Sempre achei muito confuso esse "lugar", esse circuito. Se ele tratar-se dos Museus, eu talvez tenha participado, pois a Exposição Galhos esteve em dois, sem falar na Torre Malakoff, que também recebe grandes exposições. Entretanto, se o circuito se referir àquelas mostras que ocupam grandes galerias com vernissages cheias de pompa e circunstância ou salas de museus com iluminação impecável, expografias profissionais, divulgação na mídia e texto curatorial de um grande crítico do cenário nacional, eu nunca participei. Há alguns anos atrás eu me inscrevi num edital de residências artísticas, mas meu projeto não foi aprovado e apesar de ter feito um curso de elaboração de projetos culturais, eu não me sinto segura para enviar projetos para os editais de fomento como o Funcultura e seus afins. Acho-os extremamente burocráticos. Acredito que naturalmente irei adentrar este circuito das artes em nosso estado, no Brasil e no mundo. Por hora, preciso entender as regras que comandam este jogo de oportunidades de que se trata 
o tal circuito das artes e acredito que muitas artistas trans e cis pensem da mesma forma. Precisamos ocupar estes lugares que historicamente não foram atrativos às vivências dissidentes de gênero. Espaços majoritariamente ocupados por um grupo específico de criadores que, diferente das pessoas transgêneras, dominam os códigos de produção, divulgação e escrita de projetos ligados às visualidades. Mas, este cenário está mudando e o ingresso de travestis e transexuais nas universidades alimenta-o, demonstrando que podemos, queremos e iremos ocupar a cena artística visual.

2 - (ASO) Sobre seu interesse de pesquisa hoje, o que tem te movido enquanto artista?

(BGB) Até 2019, antes de escrever o pré-projeto para a Seleção do Programa Associado de Pós-Graduação em Artes Visuais (PPGAV) UFPE/UFPE, eu atuava de forma distinta, separadamente, nos campos da militância transfeminista e das Artes Visuais. As questões de gênero não faziam parte dos temas de minhas produções artísticas, assim como os temas que levava para as palestras que realizava não tratavam diretamente de meu fazer enquanto artista. Em meados de 2019, eu senti que precisava mudar esse panorama e escrevi o projeto interligando cinetismo e questões de dissidência de gênero. Percebi que o Mestrado seria uma excelente oportunidade para entender como poderia mesclar as minhas ações militantes e artísticas. Deste pensamento nasceu o Projeto "Cadê as Travas Transcorpocinéticas?: representação do corpo de mulheres trans ou travestis por meio de uma escultura cinética", investigação na qual desejo entender como narrativas autobiográficas podem me ajudar a representar as transformações ocorridas nos corpos de mulheres trans ou travestis através de um móbile, de uma escultura cinética.

3 - (ASO) Você acredita que é possível separar artista e obra/ vida e arte a partir de seu processo de formação enquanto artista?

(BGB) - Acho que foi na Live "Como pensamos...: práticas artísticas LGBTI+ para uma educação dissidente", realizada em julho/2020 pelo Estúdio de Pintura Apotheke, que perguntei ao Prof. Dr. Fábio Rodrigues, palestrante da Live, se as artistas trans/travestis só poderiam tratar de vivências transgêneras em suas poéticas. Sabiamente o professor me respondeu que não. Para Fábio, elas não precisavam tratar apenas deste tema, mas se tratassem estariam somando forças com todo um grupo de artivistas que militam por meio da arte.

Nessa ocasião, as dúvidas comuns a toda(o) estudante que inicia o mestrado 
estavam presentes na condução de minha pesquisa. Juntamente com o pensamento transfeminista da Prof. ${ }^{a}$ Dr. ${ }^{a}$ Jaqueline de Jesus (escritora brasileira deste tema) e as importantes contribuições sobre a inclusão das mulheres na História da Arte trazidas pela Prof. ${ }^{a}$ Dr. ${ }^{a}$ Madalena Zaccara (historiadora da Arte), essa resposta me fez perceber a importância da junção entre artista e obra/vida e arte. Sobretudo levando-se em conta a realidade que as pessoas transgêneras enfrentam ao viver num dos países que mais mata essa comunidade no mundo. Realidade que torna urgente a realização de ações arte-políticas que busquem transformar esse cenário. Pensando sobre essa questão, reflito sobre a seguinte frase: para alguns artistas, "a arte é considerada política porque mostra os estigmas da dominação, porque ridiculariza os ícones reinantes ou porque sai de seus lugares para transformar-se em prática social”. Essa questão é problematiza por Jacques Rancière em seu Livro "O espectador emancipado". Logo, como deverei agir politicamente através de minhas práticas artísticas. Além disso, qualquer artista LGBTIAP+ que pretende agir politicamente através de sua arte, naturalmente toma a decisão de enfrentar esse cenário de mortes, invisibilidade e marginalidade, já que, nas palavras de Paulo Freire, "como distorção do ser mais, o ser menos leva os oprimidos, cedo ou tarde, a lutar contra quem os fez menos".

Enquadro-me nesse panorama. Então, nesse enfrentamento, assumo uma postura transfeminista que segundo Jaqueline de Jesus, no Livro Transfeminismo, "reconhece a história de luta das travestis e das mulheres trans e as experiências pessoais da população transgênero de forma geral". Sendo assim, me junto às demais ativistas aliando práticas artísticas inspiradas pelas minhas vivências à militância trans. Entretanto, acredito que também seja possível a separação entre a vida pessoal do artista e sua poética. Gosto de dobrar origamis, de modelar folhas de "coração de negro" de papel machê e de criar móbiles com gravetos de árvores. Linguagens que exprimem meu desejo de representar a natureza, algo que estaria "fora de mim". Apesar de também achar que, de alguma forma, o artista sempre irá colocar algo de si em suas práticas, afinal como diz Ailton Krenak em seu Livro "Ideias para adiar o fim do mundo", "eu não percebo onde tem alguma coisa que não seja natureza. Tudo é natureza. O cosmos é natureza”. Tudo em que eu consigo pensar é natureza". E mesmo que não trate especificamente do tema trans numa escultura ou numa pintura, a simples presença de uma criação minha, seja na parede de um museu ou na sala de estar de alguém, ainda será um ato político durante muito tempo, pois a presença dessa peça tratar-se-á de representatividade. Quem sabe num futuro próximo poderei dizer que essa frase não tem mais sentido, tamanho seja o número de artistas transexuais e travestis produzindo, vendendo, expondo, criticando ou ensinando Artes Visuais. 


\section{4 - (ASO) Como se deu o contato com a arte cinética, e como tem sido esse desdobrar de pesquisa prática e teórica sobre?}

(BGB) Se fosse responder essa pergunta através de um título, ou uma pequena frase, ela seria a seguinte: de Calder a Miro dos Bonecos, minha trajetória em torno da Arte Cinética. Bem, como juntei nesse enunciado tanto um artista americano que, de acordo com Giulio C. Argan e Rosalind Krauss, criou um pequeno circo que movia com as mãos após se estabelecer na Paris da primeira metade do Séc. XIX, quanto um artista nordestino conhecido como Mestre da Arte Popular e criador de belíssimos mamulengos, acredito ser necessário voltar ao ano de 2015, lá no inicio da minha graduação em Licenciatura em Artes Visuais, para narrar, brevemente, esse primeiro contato com a Arte Cinética e dizer como hoje tento relacioná-la com a arte de Mestre Miro.

Estava no segundo período e durante uma das aulas da disciplina Arte Brasileira foi proposto um exercício de releitura de obras. Neste mesmo momento, em História da Arte 2, estava estudando artistas contemporâneos e entre eles estava Alexander Calder. Encantei-me com seu trabalho e adaptei a releitura proposta na outra disciplina para criar uma peça móvel. A partir daí comecei a praticar com móbiles e montei a Expo Galhos que no ano de 2016 foi exibida na Biblioteca Popular de Casa Amarela. A mostra possuía 10 móbiles pendurados sob o teto ou montados sobre bases estáveis. Todos eles foram inspirados no conceito de volume virtual de Calder. Segundo Rosalind Krauss, "em seu Livro Caminhos da Escultura Moderna, o interesse de Calder é que, uma vez em movimento - girando lentamente em torno de seus pontos de conexão -, esses vetores isolados evoquem no observador um sentido de volume virtual". Essa autora ainda apresenta um relato de Calder que confirma essa teoria. Nele o escultor defende que "quando utilizo dois círculos de arame a se interceptarem em ângulos retos, isso para mim é uma esfera". Além disso, "uma obra de arte cinética móvel cria uma forma no espaço pelo movimento", atesta Cyril Barrett em seu Artigo Arte Cinética publicado no Livro Conceitos de Arte Moderna.

Bem, de posse desses conceitos segui criando e experimentando através do Cinetismo, mas quando escrevi o Projeto para o Mestrado em Artes Visuais decidi explorar a relação da Arte Cinética com as representações do corpo humano. Lembrando que Krauss defende que "é esse sentido gerado de volume que faz dos móbiles uma metáfora do corpo ao deslocar-se no espaço, mas um corpo esboçado agora pelo traço linear do construtivismo em termos de uma surpreendente transparência". Essa relação com o corpo me leva diretamente para o conceito de Esteriometria do artista russo Naum Gabo que Krauss explica através da relação entre dois cubos. No primeiro veríamos apenas uma parte de seus lados. Já no 
segundo, o Cubo Esteriométrico, teríamos acesso à estrutura interna da forma sólida, pois os lados seriam retirados. Essa foi a técnica utilizada por Gabo para criar bustos como "Cabeça Construída", de 2015.

Juntamente com a Esteriometria, outra técnica ligado ao corpo humano tem me inspirado nessa busca pela ligação entre corpo e cinetismo. Trata-se da Cronofotografia, método usado por Étienne- Jules Marey. De acordo com Marcos Buccini a Cronofotografia é "um tipo de fotografia que 'se estende' através do tempo. Não mais através de imagens borradas e indefinidas, como o movimento era representado nos primórdios da fotografia, mas a partir de uma sequência de imagens nítidas que mostrava de maneira impressionante o caminho que os corpos percorriam no espaço e no tempo".

Estas três técnicas/conceitos foram basilares para o desenvolvimento da Arte Cinética, contudo no meu estudo não bastavam apenas os conhecimentos produzidos pelos europeus/americanos. Precisava encontrar um elo com a cultura brasileira e mais particularmente com a nordestina. Lembro bem da Professora Renata Wilner ter me dito que procurasse nos mestres que fabricavam engenhocas, as referências para a pesquisa que desenvolvia. Foi dessa forma que conheci o trabalho de Mestre Miro dos Bonecos. De cara percebi que seus mamulengos poderiam me ajudar nessa tentativa de conectar a Arte Cinética e a arte dos mestres nordestinos. Assim como no Circo de Calder os mamulengos de Mestre Miro são movidos pelas mãos do artista que transfere os movimentos por meio de linhas e fios. Sendo assim eu comecei a elaborar um móbile envolvendo esses quatro elementos: o volume virtual, a esteriometria, a cronofotografia e os mamulengos. Desta forma surgiu o protótipo Seio Mamulengo-Esteriométrico, escultura cinética que representa as transformações ocorridas nos seios de mulheres trans retratando o movimento que ocorre quando elas partem do peitoral reto considerado "masculino" em direção aos seios arredondado e volumoso considerado "feminino". Essa peça faz parte de uma obra maior que, baseada nestas quatro teorias/conceitos/práticas, orientará a construção da escultura móvel "O Torso da Trava Transcorpocinética", produto da investigação que realizo no PPGAV UFPE/ UFPB.

5 - (ASO) Como você descreve a importância da reparação na história da arte que vem ganhando força sobre as novas narrativas que estão se tornando visíveis?

(BGB) Sempre que visitava museus, galerias e demais espaços dedicados às artes visuais, eu ficava me perguntando onde estavam as representações dos corpos trans. Foi então que percebi algumas coisas e comecei a me fazer algumas 
perguntas: Porque esses locais são pouco frequentados por pessoas transgêneras? As suas representações não são interessantes? As pessoas que as produzem têm acesso ao circuito da arte? Além dessas perguntas entendo que essa ausência tem ligação direta com o contexto social no qual travestis e mulheres transexuais estão inseridas. De acordo com Renata Felinto dos Santos (2019), professora e pesquisadora do revisionismo histórico, a marginalidade, invisibilidade e exclusão impostos a certos grupos humanos silencia/apaga suas criações, como foi o caso da "violência da escravidão que se transmuta em violência da subcidadania que, por sua vez, se converte em sub-representação".

Logo, para mudar essa realidade precisamos agir de forma revisionista. A Professora Madalena Zaccara diz que essa revisão precisa promover uma intervenção feminista na História da Arte para denunciar e modificar o sexismo presente no discurso fundamentado no patriarcado. Já Hans Belting, em seu Fim da História da Arte defende a mudança do paradigma que constrói a História da Arte. Para o autor "delineia-se o fim de uma tradição, que desde a modernidade se tornara o cânone na forma que nos foi contada". Desta forma, práticas artísticas que não enquadravam-se no que determinava a História da arte passam a cobrar o seu lugar de direito atuando fora dos padrões até então vigentes, pois "é sintomático que há algum tempo os artistas queiram abandonar, como eles dizem, 'os quadros rígidos' dos regimes artísticos", nos escreve Belting.

Esse movimento não atinge apenas as produções, mas inclui o próprio corpo, a presença de artistas que historicamente foram invisibilizadas. Durante muito tempo o corpo feminino foi retratado nas obras, pinturas e esculturas, que mostravam-nas quase sempre nuas. Pegando a deixa nessa questão, as Guerillas Girls fazem a pergunta que agita todo esse movimento revisionista: será que para entrar nos museus precisamos estar nuas? Esse questionamento me leva a fazer outra pergunta: onde estão as artistas trans? Será que para ter atenção elas precisam ser violentadas? Faço essa pergunta baseando-me na excessiva atenção que é dada a casos em que as pessoas trans são agredidas. Considero importantíssimo denunciar esses casos, no entanto precisamos ocupar as manchetes com nossa produção intelectual, artística e nos demais campos do conhecimento.

Acho que foi aqui no salão de beleza que um de meus clientes falou de uma pessoa que estava quebrando esse cenário de exclusão. Tratava-se de Guilhermina Velicastelo, a primeira mulher trans a concluir o PPGAV UFPE/UFPB. Lembro-me de ficar muito excitada e empolgada com essa notícia, pois vi que era possível adentrar estes espaços antes nunca imaginados para uma pessoa trans. Pouco tempo depois diversas ações foram gradualmente incluindo a comunidade transgênera em suas atividades. Entre elas posso destacar a 2a Edição do Festival Transborda de Cultura Transgênera, do qual fui madrinha, co-curadora e curado- 
ra da Expo Coletiva Serquererdizer. Mostra que contou com mais duas curadoras trans, a Sophia William e a Aurora Jamelo e mais alguns artistas da comunidade LGBTIAP+.

Este panorama foi um grande incentivador para a decisão de participar do processo seletivo para o PPGAV UFPE/UFPB. Quando fui aprovada eu vibrei e me emocionei, pois percebi a importância de minha presença numa pós-graduação no campo das artes. Momento no qual poderei cooperar com a erradicação dessa ausência de visualidades que representem os corpos trans e consequentemente causar impressões inclusivas em outras visitantes trans. Pessoas que, ao adentrarem museus ou outros espaços destinados às artes visuais, poderão encontrar corpos como os seus retratados entre as peças expostas. Mas além destes lugares pretendo adentrar locais como ONGS, expandindo o alcance do conhecimento que produzi para além dos espaços institucionais. Desta forma, chegando mais perto do público que pretendo atingir, as pessoas pertencentes à comunidade LGBTIAP+.

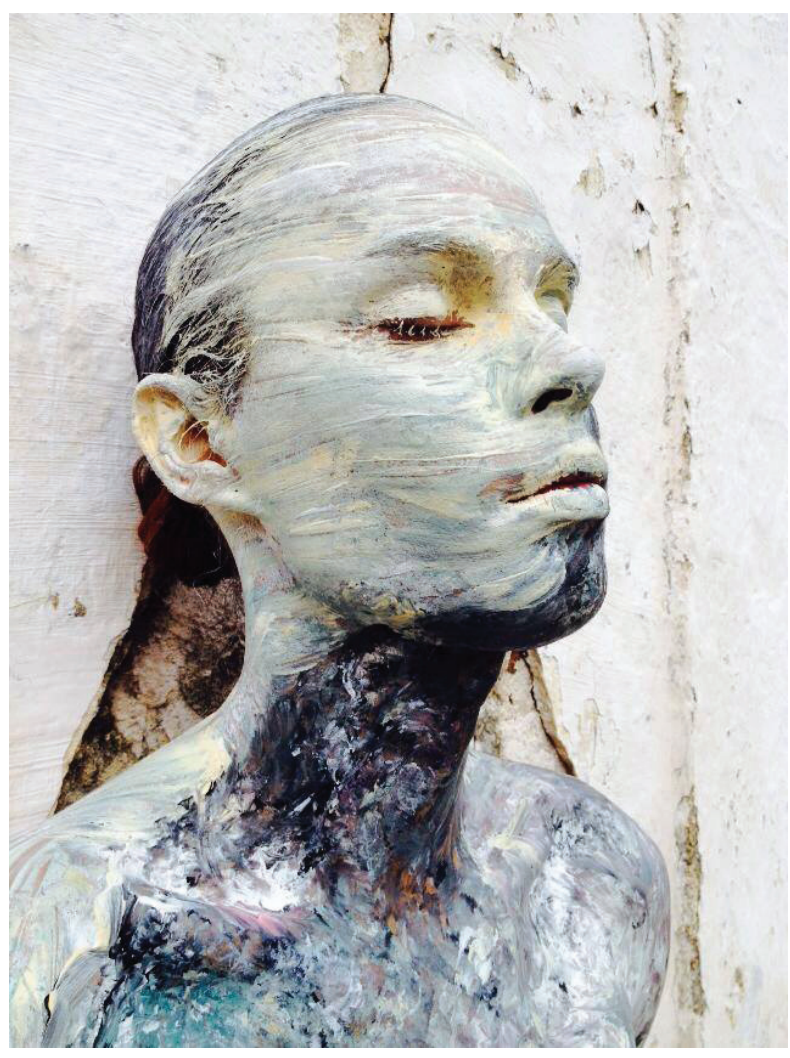

Revista do Programa de Pós-gradiação em Artes Visuais UFPE-UFPB

N. 8,2020

\section{A entrevista está disponível em nosso Podcast no Spotfy. Acesse via mobile:}

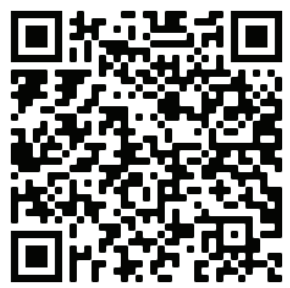

ou pelo link:

https://open.spotify.com/ episode/5r3B6ToTKVNMCZRwS75Hww
Mimetismo.

Brenda Bazante 